the other hand, the activities of the Committee on Scientific Aids to Learning have had to be suspended, and its director has been loaned to the Office of Scientific Research and Development, which is assuming much of the burden carried by the National Research Council during 1917-18. In view of the uncertainty now prevailing in world conditions, total appropriations from the British Dominions and Colonies Fund were less than in any year since 1927.

The report also includes a review of the contributions of the Corporation to the development of public and academic libraries and an analysis of a summary of the total grants made by the Corporation since 1911. Of this total of $185,000,000$ dollars, $70,000,000$ dollars were made to agencies or enterprises established by $\mathrm{Mr}$. Carnegie himself or growing immediately from them ; $48,000,000$ dollars to 848 universities, colleges and schools; 50,000,000 dollars to 777 associations, museums, libraries and agencies for research and study. More than 60 per cent of this 50 million dollars went to 22 agencies, particularly the National Academy of Sciences, including the National Research Council and the Committee on Scientific Aids to Learning (8,005,678 dollars), American Library Association (3,373,050 dollars), New York Academy of Medicine (1,625,190 dollars), American Council of Learned Societies (595,550 dollars) and Institute of International Education (1,354,979 dollars).

\section{MEASUREMENT OF LIGHTNING}

$\mathrm{N}$ an article on the measurement of lightning in 1 relation to telephone cables (Bell Lab. Rec., 21, No. 4 ; Dec. 1942), J. J. Mahoney, jun., describes some simple forms of apparatus used to ascertain the magnitude of lightning surges striking selected or other structures.

In a lightning prone area, near Lakewood, New Jersey, a number of steel masts were connected to about four miles of cable, buried for lightning tests in 1939 and not connected in any way to the Bell System plant. A tall steel mast is attached to the top of a wooden pole to direct lightning to buried telephone cables. The lightning current is conducted over a wire to an adjacent shorter pole on which measuring equipment is installed.

The tests include measurements of the crest value of the lightning current entering the cables, steepness of the wave front, the quantity of electricity in the lightning surge and the crest voltage across the insulation of the buried cable conductors. When plant damage occurs, an attempt is made to correlate it with the characteristics of the observed stroke. The ability of bare copper wires of various sizes to carry lightning current is being studied incidentally.

Since months may pass before a stroke is observed, simple inexpensive devices must be used. Their record is in the permanent magnetism given to them by the lightning. In one form, the magnetic links are straight pieces of laminated iron, each about $1 \frac{1}{2}$ in. long, enclosed in a Bakelite shell, mounted so as to intercept a magnetic field of greater or less strength, depending on their distance from the conductor, and so record currents from 500 to $10,000 \mathrm{amp}$. The links are calibrated in advance by determining the intensity of magnetization given to them by known currents.
The wave front steepness of a lightning surge is ascertained by inserting a magnetic link in a coil which is coupled with the lightning conductor. The apparatus has a rectangular loop of wire, one side of which is wound as a solenoid to enclose the link. When mounted a short distance from a conductor carrying a lightning surge, the link becomes magnetized and measures the peak current in the test circuit. From this and the crest value of the current in the lightning conductor, the time when the crest value of the discharge current is reached can be calculated from the resistive and inductive constants of the test circuit. Three loops are usually used at different distances from the conductor in order to increase accuracy of measurement.

The electrical charge of a lightning stroke is found by connecting a resistance in series with the lightning conductor and shunting an inductance across the resistance. The crest value of current in the inductance is measured by a magnetic link, and the charge then calculated from the product of the current and the inductance divided by the resistance. Peak voltages produced in telephone conductors by lightning are measured by a klydonograph, which consists of a blunt electrode in contact with the emulsion of a photographic plate backed with sheet metal and protected by a light-tight housing. The approximate magnitude and the polarity of the applied voltage can be determined by the size and appearance of the figure appearing on the developed plate. To measure the ability of lightning current to fuse bare copper wires of different gauges, several short lengths are connected in series on a terminal strip and inserted in the lead from each mast. Arcs between the ends of bent wires carry the discharge past test wires which have fused.

All the instruments used are simple to install, inexpensive and require no attention except that they are checked after each lightning storm by bringing a pocket compass near the links to test them for magnetism. Those found magnetized are removed for more accurate tests, and the photographic plates of the voltage recorders in the circuits affected are developed. The cable conductors are checked at the same time to detect plant damage.

Of three lightning strokes which have hit this experimental plant, only one struck a mast and splintered it slightly. This occurred in July 1939, before the buried cable and measuring equipment were installed. The second stroke came in October of the same year, striking a tree and entering a test cable near it by arcing from the tree's roots. The nearest measuring equipment, approximately $500 \mathrm{ft}$. away, recorded a crest current of 12,000 amp. The cable was considerably damaged. A third stroke occurred in July 1941. It also hit a tree and the lightning current entered the same cable through tree roots. Peak currents from this stroke varied from about 1,600 to $11,000 \mathrm{amp}$. at different points of the installation. Voltages ranged from 2 to $10 \mathrm{kV}$. and the quantity of electricity from 1 to 4 coulombs. Surge recorders showed that the time from start to crest of the discharge was 16 usec. Bare copper wires of 24 and 28 gauge fused on the poles nearest the tree hit. A steel culvert conducted current to the cable buried north of the road. The cable which was struck was about $\frac{1}{2}$ in. in diameter, including its lead sheath, and was enclosed in a vulcanized rubber covering about $1 / 16$ in. thick. Small puncture marks were found in the rubber where the lightning current entered the sheath. No other damage was found. 